\title{
PSICOANÁLISIS Y FEMINIDAD. EL VÍNCULO MADRE E HIJA
}

$M^{a}$ Dolores Navarro

Para hacer un abordaje de la sexualidad femenina desde la óptica psicoanalítica, las aportaciones de Freud siguen siendo un referente ineludible a pesar de sus defectos y de las críticas que suscitan. Él mismo las consideró inacabadas e invitó a que otros continuasen trabajando. Las mujeres han tenido un lugar especial en la génesis del psicoanálisis; Freud empezó a pensar a partir de una serie de casos de mujeres con patología histérica, muy frecuente en la época. También en nuestros días las mujeres ocupan un lugar primordial en nuestras consultas. Son muchas las que consultan y nos cuestionan con sus quejas sufrimientos e insatisfacciones. Por otra parte las enormes transformaciones en los modos de vida de la sociedad contemporánea, en los que las mujeres se hayan profundamente implicadas, están ocasionando nuevos dramas subjetivos y nuevos síntomas que constituyen un eficaz impulso a seguir pensando y trabajando.

El psicoanálisis deja sin respuesta a la posible pregunta acerca de qué es una mujer, puesto que únicamente estudia el proceso mediante el cual a partir de un niño indiferenciado se llega a un individuo constituido como hombre o como mujer. No hay en el inconsciente representación de lo masculino y lo femenino que simbolice la división sexual. No existe lo femenino como algo dado y establecido ni es válida la idea de la mujer en sentido general. Cada mujer se constituirá como una a partir de su propia historia y según la red de identificaciones que a lo largo de dicha existencia pueda ir construyendo. Esta es una aportación revolucionaria de Freud, en un tiempo en que la identidad sexual estaba unida a la diferencia biológica.

Freud sitúa el complejo de Edipo en el centro de su teoría. El atravesamiento de dicho complejo nos permitirá el acceso a la neurosis y será la base de la 
estructuración psíquica. La elección del objeto amoroso también estará marcada por él, puesto que elegimos la pareja amorosa en función de algún rasgo de alguno de los padres. También permitirá el acceso a la genitalidad, donde no se accede por maduración biológica exclusivamente.

El pene toma el valor de símbolo fálico y permite clasificar los sexos en función de tener o no tener. En torno a este símbolo se ordena el complejo de Edipo y el complejo de castración. En “La organización genital infantil” (1923: 2695-2697) Freud habla de etapa fálica pero es importante destacar que ya no trata de pene sino de falo. El falo es reconocido como algo diferente del pene. El niño y la niña se ven afectados de diferente manera por este símbolo. Ambos se ven afectados por la castración pero de diferente modo. La falta, que tiene un lugar central en la edificación del deseo sexuado, no afecta del mismo modo al niño y a la niña. Aunque Freud era consciente de que había tomado la evolución del niño como modelo, se daba cuenta de que la de la niña no era equiparable. No logra profundizar en esa diferencia hasta su artículo "Algunas consecuencias psíquicas de la diferencia sexual anatómica” (1925: 2896-2903). La niña se imagina haber sufrido un daño corporal aunque en realidad no le ha pasado nada. La llamada “envidia del pene” tendrá un efecto estructurante en el acceso a la feminidad. La niña culpa a la madre de haberla traído al mundo insuficientemente dotada. Este defecto de identidad no deja, según Freud, otra vía que la identificación con la madre a pesar de que ésta también está devaluada a los ojos de la niña. En este momento es cuando la niña, desilusionada de la madre vuelve sus ojos al padre y entra en el Edipo propiamente dicho, convertida en una pequeña mujer.

Es en 1931 cuando Freud, enfermo ya y con una edad avanzada, publica un texto que resulta clave para entender la feminidad. Se trata de "Sobre la sexualidad femenina” (1931: 3077-3089) texto donde profundiza en la prehistoria del Complejo de Edipo y donde sitúa la relación madre hija en el lugar que le corresponde, reconociendo que hasta ese momento no la había considerado suficientemente. Llega a decir que no es posible comprender a la mujer si no se tiene en cuenta dicha relación. La compara con una incursión en la prehistoria, etapa previa a la escritura e indescifrable. Descubrir la 
vinculación de sus pacientes mujeres con el padre era fácil pero no era tan fácil descubrir la vinculación con la madre:

En la consulta es frecuente encontrarnos con esta dificultad. Es el caso de una paciente en torno a los treinta y cinco años, que viene a consulta aquejada de serias dificultades para lograr una vida autónoma y para afianzar una vida amorosa en la que ha sufrido serios avatares. Ha tenido varias relaciones amorosas pero a ninguna de ellas ha podido darle continuidad. Vive con sus padres a pesar de las dificultades que tiene con ellos. El odio hacia la madre está instalado en el centro de su discurso, describiéndola como manipuladora, dañina, controladora, acaparadora etc. Fue necesario un tiempo de trabajo hasta que pudo descubrir la fuerte vinculación no sólo de odio sino también de amor que tenía con ella.

Freud habla de una represión inexorable sobre esta vinculación amorosa primitiva y se pregunta qué es lo que hace que una mujer abandone a la madre para interesarse por el padre. Se encuentra ante la hazaña de explicar esto, que es la clave del destino femenino, a partir exclusivamente de la envidia del pene. La madre fue el primer objeto de amor para ambos sexos. En un futuro el varón amará a la madre a través de otra mujer, pero la mujer deberá pasar del amor a la madre a interesarse por el padre y de ahí deberá renunciar de nuevo para amar al hombre. Es como un trabajo de trapecista en el que cuando ya se ha agarrado a algo debe soltarse, lanzarse al vacío y agarrarse a otro. De todos estos saltos, el salto mortal, el más difícil es el que realiza desde la madre al padre.

La pasión primitiva por la madre la deja marcada de por vida. El gran amor de la niña fue su madre y esto se verifica una y otra vez en el análisis de mujeres, aunque por otra parte sea un amor muy difícil de declarar. Se descubre más bien en las dificultades y vicisitudes con sus objetos amorosos. Quedarse en el amor a la madre no tiene salida, si no rompe este vínculo la salida es la psicosis. Para acceder al padre debe hacer el duelo por este amor, pero no es fácil desprenderse de un nudo tan fuerte. Al final de este proceso nos encontramos con la mujer que ha accedido a la feminidad. Freud da tanta importancia a esta antigua fijación de la hija a la madre que cuestiona el 
carácter universal que había dado al enunciado según el cual el complejo de Edipo es el núcleo de toda neurosis. Algo así como que las neurosis de las mujeres podrían estar en otro lado.

Cuando se separa de la madre y se aferra al padre, éste debe estar ahí para sostenerla. Debe ser un padre suficientemente válido. Debe ser un padre que esté vivo, no basta con un padre simbólico. La niña siempre anda buscando en quien depositar su amor y en este momento el padre debe hacerse digno de convertirse en este continente. El amor a la madre le vino dado como una especie de destino pero ahora se trata de hacer una elección y el padre debe resultar merecedor de dicha elección. De esto dependerá el acceso a un amor encarnado en el deseo. Es necesario que el padre erotice a la hija como un proyecto de mujer. Dicha erotización deberá serlo en su justa medida. Si es excesiva o insuficiente se traducirá en dificultades para la vida futura de la hija. En la pubertad la niña necesita ser mirada por el padre y luego por el hombre y despertar amor. Parecería que el amor por el otro puede depender de la imagen del amor despertado por ella. (Assoun, 1994: 11-52) Más adelante la niña deberá renunciar al padre para acceder al amor del hombre, eligiendo uno distinto al padre que llevará alguna marca que recordará a sus antiguos amores, pero que a la vez será diferente a ellos y por eso lo amará, al menos mientras sea capaz de encarnar la función de ideal.

Una mujer de mediana edad, atractiva y distante viene a consulta a raíz de unas entrevistas realizadas en otro lugar por problemas con su hija pequeña. Tiene muchas dificultades para vivir la sexualidad con su marido de forma satisfactoria. Inicia un análisis en el que puede hablar del abandono sufrido por su padre cuando ella era niña. El padre dejó a la madre y a sus cuatro hijos y pasó a vivir con otra mujer que tenía ya un hijo. Ella no quiso volver a hablar con él. Se cruzaban por la calle y no se saludaban. Lo arrancó literalmente de su cabeza. No sentía por él ni amor ni odio. Siempre pensó que no le importaba y que no le había afectado dicho abandono. Después de cierto tiempo de análisis empieza a pensar en él. De vez en cuando se le viene a la cabeza sin pretenderlo. En una ocasión tiene un sueño en el que un hombre con dos muletas le obstruye el paso pero logra salir a la calle y respirar aire fresco. Entonces algo empezó a mejorar. 
Para esta mujer y otras muchas que han encontrado serios tropiezos en la construcción de su feminidad, el análisis se convierte en un instrumento imprescindible.

Imaginemos una especie de vasos comunicantes donde el contenido va pasando de uno a otro. Por esto, de un intenso apego idealizado al padre o al hombre se puede deducir una idealización similar dirigida hacia la madre, aunque esté oculta y sepultada por la represión.

Pero la problemática femenina no es otra que el retorno a la antigua relación con la madre. En “Análisis terminable e interminable” de 1937, Freud llega a decir que la envidia del pene tiene algo de irreductible, lo que implica que el retorno a la madre, con toda la ambivalencia que esta relación tiene, sigue siendo inevitable en el destino de la niña. Es decir que la aparición del padre no hace que desaparezca totalmente la madre. Una especial dificultad para la niña radica en que cuando debe renunciar a la madre como objeto de amor, es decir cuando la madre le despierta la mayor hostilidad es sin embargo cuando debe identificarse con ella para ocupar su posición femenina con respecto al padre.

Para Lacan, por el contrario, la madre no puede aportar a la hija un rasgo unitario que sostendría su identidad, por la razón de que no existe el significante de la identidad femenina. La niña debe enfrentarse a esa falta radical en el Otro que redobla su castración. La madre por una parte no puede darle el significante de una identidad femenina porque no existe y por otra tampoco tiene el falo ni puede dárselo. Su falta es doble. De aquí se deduce la enorme hostilidad de que está teñido el complejo de castración en la niña. También aquí estaría la explicación de que la vida sexual femenina esté tan centrada en el amor y en la demanda de amor, es decir en la demanda de que el Otro le dé lo que no tiene (André, 2002: 185-191).

A pesar de que Lacan se desmarca de Freud en el tema del acceso a la feminidad por identificación, coincide con él en lo problemático de la relación de la hija con su madre. Utiliza la palabra ravage traducida como “estrago” o “devastación” para referirse a la especie de arrancamiento que la hija debe de hacer de la madre (Lacan, 
1976: 21). Cada mujer deberá debatirse con el lazo que la une a su propia madre para así poder acceder a identificaciones femeninas o maternales. El estrago se puede presentar en la crisis de la adolescencia o en momentos donde el ser mujer se pone en juego, como la maternidad, el parto, el acto sexual, o el aborto. En estos momentos la mujer puede verse invadida por un exceso que la desborda o tener la impresión de estar fuera de sí o presa. Es un estado en el que está comprometido el cuerpo. Son estados que vuelven loca a la mujer. Se trata de un goce al que se ha llamado "goce de la madre” pero que nada tiene que ver con un estado placentero (Chatel, 1996: 45-50).

Lacan, lo mismo que Freud, considera a esta antigua y estrecha vinculación con la madre, y a las dificultades para salir de ella, como lo específico de la feminidad. El padre donador del falo sería secundario con relación a otra cosa más sustancial que es el doloroso estrago que se experimenta entre madre e hija. Estos estados de reproche y disarmonía son recíprocos pero no equivalentes. Tienen su origen en un exceso de proximidad entre ambas. Atravesar la dolorosa experiencia del estrago saca a la mujer del goce de la madre. Supone abandonar la ilusión de compartir la experiencia femenina entre madre e hija y de reconciliación o armonía entre ambas.

Por otra parte, libera en cierta medida a la hija del pago al que se siente obligada para calmar la rabia de la madre. En este pago se encuentra el origen de sacrificios que hace la hija, plasmados en pérdidas a nivel del real del cuerpo, abortos o como se observa a veces en entornos rurales, en la cesión a la madre de uno de los hijos. El pago tiene que ver con el intento de terminar con esa relación devastadora. En ocasiones, la violencia toma la forma de un cuerpo a cuerpo. Dicha violencia es mayor en la medida en que la hija tiene un lugar único para la madre, como un lugar de encantamiento. El encantamiento es lo opuesto al estrago. Los aspectos subjetivos e inconscientes, objeto de estudio del psicoanálisis, que constituyen la clave para el acceso a la feminidad, se encuentran entrecruzados con el orden cultural, de ahí que la única manera de definir la feminidad es como el resultado de la articulación entre lo inconsciente con la cultura. 
El psicoanálisis es liberador porque no dice nada de lo que es o debe ser una mujer. La categoría mujer no es más que una ficción. El psicoanálisis sólo entiende de diferencia sexual. Desmontar la categoría mujer deja libre a las mujeres para que se construyan según el juego de identificaciones que vayan realizando a lo largo de su vida, alejándose de cualquier identidad de género predeterminada. Definir la esencia de la feminidad y pretender que las mujeres se adapten a ella, no es más que una forma de violencia.

Es innegable que en el ámbito de lo cultural el feminismo ha realizado un enorme trabajo por desmontar las representaciones tradicionales de la identidad femenina en una sociedad patriarcal, demostrando que son producto de una ideología. Actualmente existen amplios espacios donde psicoanálisis y feminismo colaboran en que las mujeres logren un lugar de sujeto desde el que poder hablar y actuar modificando las condiciones de su propia existencia (Tubert, 2001: 125).

Las importantes transformaciones que está sufriendo la sociedad contemporánea en lo que a modos de vida se refiere están ocasionando nuevos dramas subjetivos y nuevos síntomas. La movilidad en las relaciones de pareja, las posibilidades para abortar, las nuevas técnicas de fertilización, la adopción, el acceso cada vez mayor de la mujer a puestos de poder social y económico, el cambio de posición frente a la sexualidad abordándola de una forma más natural y desinhibida, etc., son factores que están provocando grandes modificaciones a nivel subjetivo y cultural.

Las mujeres que han accedido a un lugar en la vida pública, en la política o en la cultura y que no han renunciado a la maternidad y a la vida familiar, lo han logrado con el precio de una enorme exigencia y sobrecarga. Son mujeres que se exigen dar al máximo en cada uno de los lugares que ocupan. Ser buena madre, buena esposa, buena profesional, estar al día, estar en forma y atractiva... parece demasiado y se corre el riesgo de que todo ello se convierta en una trampa que la deje borrada como sujeto. 
Una mujer próxima a los sesenta consulta porque desde hace algún tiempo se siente mal. Ha empezado a tomar medicación y se siente deprimida y sin ilusión. Llama la atención la sensación de sobrepeso que transmite, unos kilos de más y un enorme peso psíquico que dan a su figura una postura encorvada. En la primera entrevista habla de su marido y de las dificultades de sus hijas. Cuando ha transcurrido casi toda la sesión le digo que no me ha hablado de ella. Entonces enumera una serie de actividades que yo comparo con la lectura de un listín telefónico. A partir de ahí es cuando empieza a hablar de su falta de ilusión por todo. Ocupa un alto puesto directivo en una empresa al que ha dedicado gran parte de su vida y de su energía, pero ahora se siente allí poco más que "un número o una silla”. Las necesidades de la empresa y la llegada de nuevas generaciones han provocado que las cosas ya no sean como antes.

En sesiones sucesivas habla de su lucha para poder estudiar en una familia donde se daba preponderancia al varón y luego para trabajar y lograr el puesto que ocupa. Muy joven empezó a trabajar, se casó tuvo hijos, cuidó a sus padres, cuidó a sus suegros y trabajó y trabajó; siempre hacer y hacer. Habla de agotamiento y de soledad, de falta de cariño, de amigos perdidos porque no ha tenido tiempo de cuidarlos. Desconfía de que el tratamiento la pueda ayudar. Después de algunas sesiones las exigencias de plena disponibilidad por parte de su trabajo y su dificultad para renunciar a algo hicieron imposible continuar.

Colette Soler, en su libro Lo que Lacan dijo de las mujeres (2006), observa que el unisex está alcanzando también a la sintomatología y la separación entre objeto de amor y objeto de deseo que Freud diagnosticó en los hombres, también afecta hoy a las mujeres. Ahora que el matrimonio no es la única opción, aparecen mujeres que aman por un lado y desean por otro.

También aparecen nuevas inhibiciones. Se aplaza el momento de tener un hijo y se aplaza el compromiso con el hombre. Este aplazamiento, unido al deseo lleva a las mujeres a las consultas. La juventud parece que se prolonga pero el reloj biológico sigue su curso. Mujeres solteras que llegando a una determinada edad se encuentran ante la disyuntiva entre tener un hijo solas o encontrar pronto un hombre. Ahora la contracepción, la legalidad del aborto separan más que nunca reproducción y sexualidad.

Por otra parte es cada vez más frecuente que la madre sea el acompañante exclusivo del niño. Madres con niño al que eventualmente se suma un hombre o varios. 
Psicoanálisis y feminidad. El vínculo madre e hija

Ya empiezan a entreverse las consecuencias subjetivas que esta nueva relación madre hijo indudablemente va a aportar.

Nota: Esta conferencia fue presentada el 24 de noviembre de 2006 en la Facultad de Ciencias de la Educación en Córdoba, en las jornadas “Freud, 150 años después”. 


\section{BibliOgRAFíA}

André, S. (2002): ¿Qué quiere una mujer? México: Siglo Veintiuno.

Assoun, P. L. (1994): Freud y la mujer. Buenos Aires: Nueva Visión.

Chatel, M. M. (1996): El malestar en la procreación. Buenos Aires: Nueva Visión.

Freud, S. (1923): La organización genital infantil ( Vol. III, pp. 2698-2700). Madrid:

Biblioteca Nueva.

-(1925): Algunas consecuencias psíquicas de la diferencia sexual anatómica (Vol. III, pp. 2896-2903). Madrid: Biblioteca Nueva.

-(1931): Sobre la sexualidad femenina (Vol. III, pp. 3077-3089). Madrid: Biblioteca Nueva.

Lacan, J. (1976): “L’étourdi”, en Scilicet, n 4. Paris: Seuil (“El atolondraducho”, en Escansion, $n^{\circ}$ 1, Buenos Aires/Barcelona, Paidós, 1984).

Soler, C. (2006): Lo que Lacan dijo de las mujeres. Buenos Aires: Paidós.

Tubert, S. (2001): Deseo y representación. Convergencias de psicoanálisis y teoría feminista. Madrid: Síntesis. 